\title{
Prognostic Relevance of Ww-Oxidoreductase Gene Expression in Patients with Acute Lymphoblastic Leukemia
}

Walaa Fikry Elbossaty ${ }^{1^{*}}$, Camelia .A.Abdel-Malak ${ }^{1}$ and Doaa M.Elghanam ${ }^{2}$

${ }^{1}$ Department of Chemistry, Biochemistry Division, Faculty of Science, Damietta University, Damietta, Egypt ${ }^{2}$ Mansoura University Hospital, Mansoura, Egypt

\begin{abstract}
Background: The WWOX gene (WW-Oxidoreductase) gene is frequently lower expressed in variety of tumor.

Methods: Screening for WWOX gene expression was assessed using real-time reverse transcriptase polymerase chain in $50 \mathrm{ALL}$ cases and 50 healthy control.

Results: WWOX gene was significantly lower in ALL cases $(0.43239 \pm 1.38925)$ when compared with healthy control $(10.501 \pm 9.0338)(p=<0.001)$. No significant differences were found between high and low WWOX gene expression regarding clinical data, age, sex, hematological data. Patients who highly expressed WWOX gene achieved $C R$ at significantly higher rates in $A L L(p=0.002)$, and had significantly lower frequency refractory disease in ALL patients $(p=0.017)$. Higher expression WWOX gene patients have statistically longer OS $(p=0.049)$ when compared with low expression WWOX gene patients.
\end{abstract}

Conclusion: Our result suggested that WWOX gene was a predictor for better outcome, could be a useful target for immunotherapy and might represent a candidate marker for monitoring of minimal residual disease.

Keywords: WWOX; ALL; Hematological data; Tumor suppressor gene

\section{Introduction}

Acute lymphoblastic leukemia (ALL) is a form of leukemia, or cancer of the white blood cells characterized by the overproduction of cancerous, immature white blood cells-known as lymphoblasts [1]. Malignant, immature white blood cells continuously multiply, causing damage and death by inhibiting the production of normal cellssuch as red and white blood cells and platelets-in the bone marrow and by spreading (infiltrating) to other organs. Acute Lymphoblastic leukemia (ALL) encompasses a group of lymphoid neoplasms that morphologically and immunophenotypically resemble B-lineage and $\mathrm{T}$-lineage precursor cells. These neoplasms may present predominantly as a leukemic process, with extensive involvement of the bone marrow and peripheral blood or may be limited to tissue infiltration, with absent or only limited (less than 25\%) bone marrow involvement [2]. The latter cases are typically designated as Lymphoblastic lymphomas (LBLs). ALL and LBLs appear to constitute a biologic continuum, although they may show distinct clinical features. The current World Health Organization Classification of hematopoietic neoplasms designates these disorders as B- or T-lymphoblastic leukemia/lymphoma [3]. The WW domain-containing Oxidoreductase (WWOX) gene is located at 16q23.3-24.1, a region that spans the second most common human fragile site, FRA16D [4]. The name for this newly identified gene comes from the fact that it has two WW domains coupled to a region with high homology to the short chain dehydrogenase/ reducates family of enzymes [5]. Genomic analysis has revealed that WWOX contains 9 exons encoding an mRNA that is $2.2 \mathrm{~kb}$ long, which encodes a 46 $\mathrm{kDa}$ WWOX protein containing 414 amino acids [4]. The full-length WWOX, which encodes a 414 amino acid protein, possesses two typical N-terminal WW domains (first domain, amino acids 17-49; second domain, amino acids 58-90), a C-terminal short-chain dehydrogenase reductase (SDR) domain, and a nuclear localization sequence (NLS) [6]. Additionally, an NSYK (Asn-Ser-Tyr-Lys) motif for binding with sex steroid hormones, a nuclear localization signal (NLS) (GKRKRV), and a mitochondria-targeting sequence in the ADH/SDR domain have been defined in WWOX [7]. The first N-terminal WW domain is needed for the classical WW-PPXY interaction [6]. The first WW domain binds target proteins containing the proline-rich PPXYmotif (s) during signal transduction. For example, WWOX interacts with p73, activator protein $2 \gamma$ (AP-2 $\gamma$ ), ErbB4, ezrin, small integral membrane protein of the lysosome/late endosome (SIMPLE), and c-JUN transiently over expressed WWOX blocks the nuclear accumulation of p73, AP- $2 \gamma$, and c-JUN in vitro [8]. While presumed that mutation of p73 might lead to production of defective p73 protein and this might have a role in the process of leukemogenesis of ALL [1]. In the Wnt/ $\beta$-catenin pathway, transiently over expressed WWOX prevents nuclear import of dishevelled [6]. Similarly, in the HGF/MET pathway, ectopic WWOX inhibits the MET C-terminal fragment for nuclear translocation and suppression of the downstream gene expression [6]. The proteins with the SDR domain are involved in oxidation and reduction of various substrates such as lipid hormones, sugars, alcohols and retinoids [6]. The gene is also called FOR, which stands for FRA16D Oxidoreductase. Alternative spliced WWOX transcripts (variants 1-8) encode proteins that share N-terminal WW domains in common but differ at their C-terminus, with variant 3 having a truncated Oxidoreductase domain. It has been suggested that proteins encoded by these variants interfere with normal WWOX function in a dominant negative fashion [7-9]. Recently, tumor suppressor's p53

*Corresponding author: Walaa fikry Elbossaty, Department of Chemistry, Biochemistry Division, Faculty of Science, Damietta University, Damietta, PO Box 34517, Egypt, Tel: 020573761683; E-mail: walaafikery@du.edu.eg

Received September 18, 2015; Accepted October 10, 2015; Published October 14,2015

Citation: Elbossaty WF, Malak C, Elghanam DM (2015) Prognostic Relevance of Ww-Oxidoreductase Gene Expression in Patients with Acute Lymphoblastic Leukemia. J Cancer Sci Ther 7: 302-307. doi:10.4172/1948-5956.1000367

Copyright: ( 2015 Elbossaty WF, et al. This is an open-access article distributed under the terms of the Creative Commons Attribution License, which permits unrestricted use, distribution, and reproduction in any medium, provided the original author and source are credited. 
and WWOX were shown to regulate the apoptosis of glioblastoma cells [10]. WWOX may act as an alternative receptor for sex steroid hormones, since its SDR domain possesses an NSYK motif capable of interacting with androgen and estrogen [10]. Under stress conditions, WWOX is activated via phosphory-lation atTyr33, and binds proteins independently of the PPxY motif [8]. Activated WWOX physically interacts with serine 46-phosphorylated p53, which stabilizes p53 and its apoptotic function [10] also, WWOX binds Disheveled proteins (Dvl), which are key componentsinWnt/b-catenin signaling pathway. No PPxY motifis in Dvl. Transiently over expressed WWOX sequesters Dvl-2 in the cytoplasm and there by blocks Dvl- 2-mediated TCF transcriptional activity [10]. There are now approximately 100 reports concerning the correlation of the loss of Wwox expression with cancer development, including some reporting association of Wwox absence with poor prognosis and outcome in various cancer types Ectopically over expressed Wwox has been reported to promote apoptosis [10], tumor suppression, suppression of anchorage-independent growth Low, undetectable expression or aberrant transcripts of WWOX were reported in several tumor cell lines of different origins [11,12].

\section{Materials and Methods}

Fifty patients ( 33 males and 17 females), newly diagnosed with ALL, were selected from oncology center, Mansoura university with written informed consent. The mean age was $38.40 \pm 13.44$ years, in addition, a control group of fifty healthy control age and gender matched, diagnosis and classification of ALL were made according to the FrenchAmerican-British (FAB) criteria and immunophenotyping analyses. the immunophenotyping was pre -B-ALL (CD19+,CD22+,CD10-), B-ALL(CD19+,CD22+,CD10+) and T-ALL (CD3+,CD5+,CD7+).

\section{End points}

Complete remission (CR) is defined as acellurity of more than $20 \%$ with fewer than $5 \%$ blasts in bone marrow (BM) after induction chemotherapy, and relapse is defined by the appearance of one of the following more than $50 \%$ lymphoblasts in asingle $\mathrm{BM}$ aspirate [13]. progressive repopulation of lymphoblasts in excess of $5 \%$ culminating in more than $25 \%$ on two or more BM samples separated by 1 week or more [14]. More than 25\% lymphoblasts in the BM and $2 \%$ or more circulating lymphoblasts [15]. Leukemic cell infiltration in extramedullary organs for example,central nervous system or in CSF with cell count greater than $5 \mathrm{WBCs} / \mathrm{mm}$. Disease -free survival (DFS) was defined only for those patients achieving a CR. it was measured from the CR date until date of relapse or death, regardless of cause, censoring for patients alive at least follow up.

\section{RNA extraction and cDNAsynthesis}

RNA was isolated from $1 \mathrm{ml}$ ALL peripheral blood by RNA blood mini kit (Qiagen, Hilden, Germany) following the manufacturer is instructions. Subsequently $0.5 \mu \mathrm{g}$ RNA was reverse transcribed in to $\mathrm{cDNA}$ in $20 \mu \mathrm{l}$ reverse transcriptase buffer containing $10 \mathrm{mmol} / \mathrm{L}$ DTT, $0.5 \mathrm{mmol} / \mathrm{L}$ each of dATP, dGTP,dCTP and dTTP, 200 units of Moloney murine leukemia virus reverse transcriptase, 5 units of Rnase inhibitor,and $5 \mathrm{mmol}$ of random hexamers (MBI Fermentas,st.LeonRot, Germany) and applied to 7000 sequence detection system at $250^{\circ} \mathrm{C}$ for $10 \mathrm{~min}, 370^{\circ} \mathrm{C}$ for $120 \mathrm{~min}$ and $850^{\circ} \mathrm{C}$ for $5 \mathrm{~min}$.

\section{Quantitive real - time (QRT-PCR)}

The mRNA expression level of WWOX and the endogenous housekeeping gene GA PDH as a reference were quantified by the RT QPCR method using ABI prism 7000 real-time PCR sequence detection system (Applied Biosystems, Foster city,CA).the sequence of primers and probes of WWOX and PCR products were amplified and detected using dual fluorescent non-extendable probes labeled with 6-carboxyfluorescien (FAM), reporter and 6-carboxyytetramethylrhodamine (TAMRA),quencher at 5'-end and 3'-end, respectively. $4 \mu \mathrm{l}$ of cDNA in each PCR reaction in a final volume of $20 \mu \mathrm{l}$ containing $900 \mathrm{nmol} / \mathrm{L}$ of sence and antisense primers (Table 1) , $200 \mathrm{nmol} / \mathrm{L}$ of the TaqMan probe, $5 \mathrm{mmol} / \mathrm{L} \mathrm{MgCl}, \mathrm{KCl}$, and Tris- $\mathrm{HCl}, 0.2 \mathrm{mmol} / \mathrm{L}$ dATP, dCTP, dGTTP, dTTP and 0.5 units of AmpliTaq DNA polymerase PCR program was $95^{\circ} \mathrm{C}$ for 10 minutes, followed by 40 cycles of $950 \mathrm{c}$ for 15 seconds and $60^{\circ} \mathrm{C}$ for 60 seconds for each patient and control. The relative mRNA expression level of WWOX was calculated using the comparative cycle method. Briefly the target PCR Ct values, that is, the cycle number at which emitted fluorescence exceeds $10 \mathrm{x}$ the standard deviation of base-line emissions are normalized to the GAPDH Ct value. Relative mRNA expression levels were calculated using the $2^{-\Delta \Delta \mathrm{Ct}}$ method.

\section{Statistical analysis}

Data were analyzed using chi-square or Fisher exact tests to analyze the expression of mRNA levels of WWOX gene between different groups. Survival curves were plotted using the Kaplan-Meier method, and differences were analyzed using $\log$-rank tests. A p-value $<0.05$ was considered significant. Logistic regression was carried out using odd ratio. Proportional hazards models were constructed to determine whether WWOX was associated with outcome when adjusting for other prognostic variables. All data analyses were done using SPSS software, version 22 .

\section{Results}

\section{Expression of WWOX mRNA in ALL patients}

In this study, the expression of WWOX mRNA was investigated in 50 ALL patients and 50 cases of healthy controls by using real -time PCR. WWOX low expression was found in 25 (50\%) of 50 patients, the difference between WWOX expression in ALL patients and healthy controls was found to be statistically significant $(\mathrm{p}<0.001)$ (Table 2)

\section{WWOX expression and clinical parameters}

Statistical evalution was performed to study potential correlations between WWOX expression and initial clinical parameters. No important correlation could be observed between WWOX expression and clinical characteristics such as age, gender, initial white blood cell count, FAB- type and blast cell percentages (Table 3). Also, there was no significant difference in WWOX expression between T-lineage and precursor B-lineage leukemia.

\section{Prognostic relevance of WWOX expression}

High expression WWOX had a statistically higher CR (23of 25; 92 $\%$ VS 15 of $25 ; 60 \%, p=0.002)$, lower refractory ( 0 of $25 ; 0 \%$ vs. 10 of $25 ; 40 \%, \mathrm{p}=0.017$ ) (Table 4). Kaplan -Meier analysis demonstrated significantly longer OS and DFS in highly expression WWOX (86.7 $\%$; vs. $56.6 \%$; 37.034 months vs. 22.998 months; $\mathrm{p}=0.041,83.6 \%$; vs. $100 \% ; 37.464$ months vs. 34.333 months $; \mathrm{p}=0.883$ ) (respectively in

\begin{tabular}{|l|l|}
\hline Primers & Primer Sequence \\
\hline Forward primer & 5'-CCCTGGAGAAGTTCACGATTC- 3 \\
\hline Reverse primer & 5'-CAGTGAGCACACTGGTGAGATT-3' \\
\hline TaqMan® Probe & 5'-FAM TACAAGTGTGTGCAGCCTGACTGT TAMRA-3' \\
\hline
\end{tabular}

Table 1: Sequence of primers and probe for WWOX gene expression. 
Citation: Elbossaty WF, Malak C, Elghanam DM (2015) Prognostic Relevance of Ww-Oxidoreductase Gene Expression in Patients with Acute Lymphoblastic Leukemia. J Cancer Sci Ther 7: 302-307. doi:10.4172/1948-5956.1000367

\begin{tabular}{|c|c|c|c|c|c|}
\hline & & & Control & ALL & $\mathbf{P}$ \\
\hline & & & $(n=50)$ & $(n=50)$ & \\
\hline \multirow{4}{*}{ WWOX } & \multirow{2}{*}{$\Delta \Delta \mathrm{CT}$} & Median (Range) & $31.07(20.2-32)$ & $33.060(21.9-41)$ & $0.011^{*}$ \\
\hline & & Mean $\pm S D$ & $28.17 \pm 5.4015$ & $33.028 \pm 4.22918$ & \\
\hline & \multirow{2}{*}{ Expression } & Median (Range) & $14.846(0.0139-20.1)$ & $0.005 .8203(5.04 \times 10-6-6.88)$ & $<0.001^{* *}$ \\
\hline & & Mean $\pm S D$ & $10.501 \pm 9.0338$ & \multicolumn{2}{|c|}{$0.43239 \pm 1.38925$} \\
\hline
\end{tabular}

Table 2: WWOX gene expression in studied groups.

\begin{tabular}{|c|c|c|c|c|}
\hline \multirow{2}{*}{ Variables } & \multicolumn{4}{|c|}{ ALL } \\
\hline & Total $(n=50)$ & $<$ median $(n=25)$ & $>=$ median $(n=25)$ & $\mathbf{P}$ \\
\hline \multirow{2}{*}{ Age } & \multirow{2}{*}{$38.40 \pm 13.449$} & 38.07 & 38.73 & \multirow{2}{*}{0.895} \\
\hline & & \pm 13.472 & \pm 13.890 & \\
\hline Male & $33(66)$ & $16(64)$ & $17(68)$ & \\
\hline Female & $17(34)$ & $9(36)$ & $8(32)$ & 1 \\
\hline Total leucocytic count (X109/L) & $48.5(3.7-225)$ & $56(3.7-134)$ & $43(4.7-225)$ & 0.0868 \\
\hline BM blast $\%$ & $56.00(23-90)$ & $65(23-90)$ & $56(24-90)$ & 0.868 \\
\hline Peripheral blasts (\%) & $45.50(16-89)$ & $45(21-89)$ & $47(16-78)$ & 0.382 \\
\hline \multicolumn{5}{|l|}{ FAB classification $(\mathrm{n}, \%)$} \\
\hline L1 & $14(28 \%)$ & $3(12 \%)$ & $11(44 \%)$ & 0.678 \\
\hline L2 & $30(60 \%)$ & $19(76 \%)$ & $11(44 \%)$ & \\
\hline L3 & $6(12 \%)$ & $4(16 \%)$ & $2(8 \%)$ & \\
\hline
\end{tabular}

Table 3: Patient's characteristics according to WWOX expression status.

\begin{tabular}{|c|c|c|c|c|c|c|c|}
\hline \multirow[t]{2}{*}{ Outcome measures } & \multicolumn{2}{|c|}{ High expression WWOX } & \multicolumn{2}{|c|}{ Low expression WWOX } & \multicolumn{2}{|c|}{ Total $(n=50)$} & \multirow[t]{2}{*}{$\mathbf{P}$} \\
\hline & $\mathrm{N}$ & $\%$ & $\mathrm{n}$ & $\%$ & $\mathrm{~N}$ & $\%$ & \\
\hline Complete remission & 23 & 92 & 6 & 24 & 29 & 58 & $0.002^{* *} \boldsymbol{\nabla}$ \\
\hline Relapse & 0 & 0 & 14 & 56 & 14 & 28 & $0.017^{*} \Delta$ \\
\hline Refractory & 0 & 0 & 7 & 28 & 7 & 14 & $0.715 \Delta$ \\
\hline Total death & 8 & 32 & 17 & 68 & 25 & 50 & $0.0269^{*}$ \\
\hline
\end{tabular}

Table 4: Comparison between high and low WWOX expressers regarding outcome measures.

\begin{tabular}{|c|c|c|c|c|c|c|c|c|c|c|}
\hline \multirow{2}{*}{ Expression } & \multirow{2}{*}{ Groups } & \multicolumn{4}{|c|}{$<$ median } & \multicolumn{4}{|c|}{$\geq$ median } & \multirow[t]{2}{*}{$\mathbf{p}$} \\
\hline & & Cumulative Survival (\%) & Mean (months) & $\mathrm{Cl} 95 \%$ & & Cumulative Survival (\%) & Mean (months) & $\mathrm{Cl} 95 \%$ & & \\
\hline ALL & OS & 56.6 & 22.998 & 14.649 & 31.347 & 86.7 & 37.034 & 29.402 & 44.666 & $0.041^{*}$ \\
\hline & DFS & 100 & 34.333 & 28.474 & 40.192 & 83.6 & 37.464 & 31.013 & 43.915 & 0.883 \\
\hline
\end{tabular}

Table 5: Survival analysis in studied cases.

comparison to low expression WWOX patients (Table 5, Figures 1-3). Applying to odd ratio of high to low WWOX expression showed that highly WWOX expressers were 2.1 times more likely to have complete remission (95\% CI:0.03-4.61; $\mathrm{p}=0.01$ ), 2.46 times more likely to relapse (95\% CI:0.187-2.41;p=0.0494) and 0.05 times more likely to refractory (95\% CI:0.01-0.32; p=0.2) than low WWOX expressers (Table 6). Multivariate analysis confirmed the prognostic value of WWOX expression as independent predictor for longer OS (HR=0.347, 95\% CI: 0.095-0.872; $\mathrm{p}=0.01$ ) (Table 7). Taken together, these results confirm the prognostic value of WWOX in ALL.

\section{Discussion}

The WWOX gene was identified recently as a tumor suppressor gene at 16q23.3-24.1, a chromosome region that spans the common fragile site FRA16D. Several studies have revealed alterations of WWOX in several types of human cancers. The present study demonstrated that a relatively low expression of WWOX correlates with complete remission and relapse diagnosis statuses in ALL patients, supporting the hypothesis that the occurrence of ALL is a progressive and multistaged process, similar to that of other tumors. In the present study, significant amount of low expression of WWOX mRNA were reported in $50 \%$ ( 25 of 50 ) of ALL. Chen X et al. found that low level of mRNA WWOX gene was detected in about $48.2 \%$ from ALL cases. Epigenetic changes contribute greatly to leukemia development. DNA methylation is a well-studied mechanism in epigenetic. The hypermethylation of numerous genes has been detected in various types of tumors and hematological neoplasms [16]. Previous studies have shown that DNA methylation is the most commonly detected alteration in ALL [17]. DNA methylation often results in the silencing of tumor suppressor genes, although the gene sequence may not have been changed. This mechanism has been identified as leading to the loss of function of numerous tumors suppressor genes in various types of tumor cells [18]. Based on these observations, it has been postulated that the inactivation of WWOX is driven by homozygous deletions or methylation status. Relative WWOX expression wasn't correlated to age, gender, WBC counts, percent of leukemic cells in peripheral blood and bone marrow in accordance with others [16]. High expression WWOX expressers showed a statistically higher CR $(\mathrm{p}=0.002)$, low relapse $(\mathrm{p}=0.08)$, and low refractory $(\mathrm{p}=0.045)$ in accordance with previous reports that have correlated high levels of WWOX expression with a favorable clinical outcome [19-22]. Kaplan-Meier analysis demonstrated significantly longer OS in highly expressed WWOX.

In summary, the methylation status of WWOX may lead to the silencing of gene expression, promoting the occurrence and development of ALL. Detecting the mRNA expression and methylation 

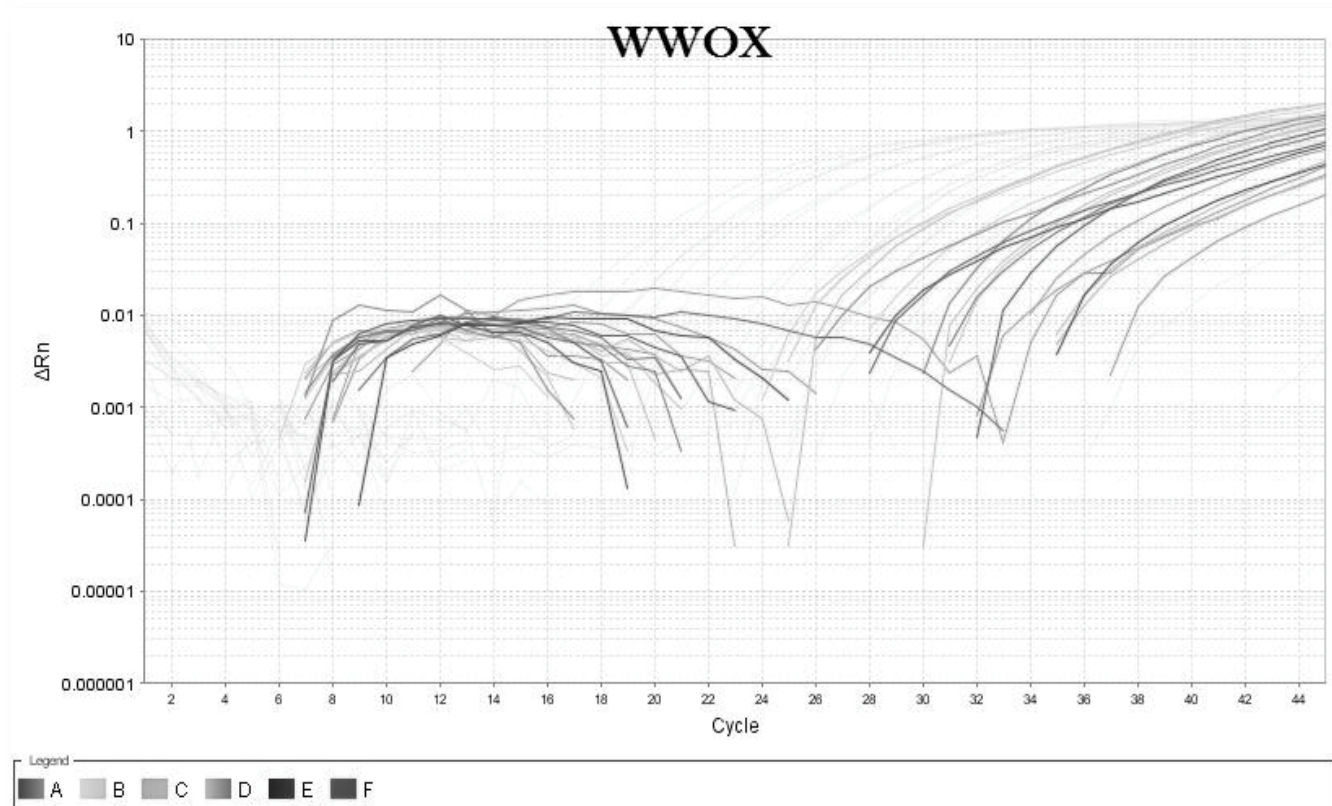

Figure 1: Amplification plots of WWOX gene and GAPDH by using RT-PCR

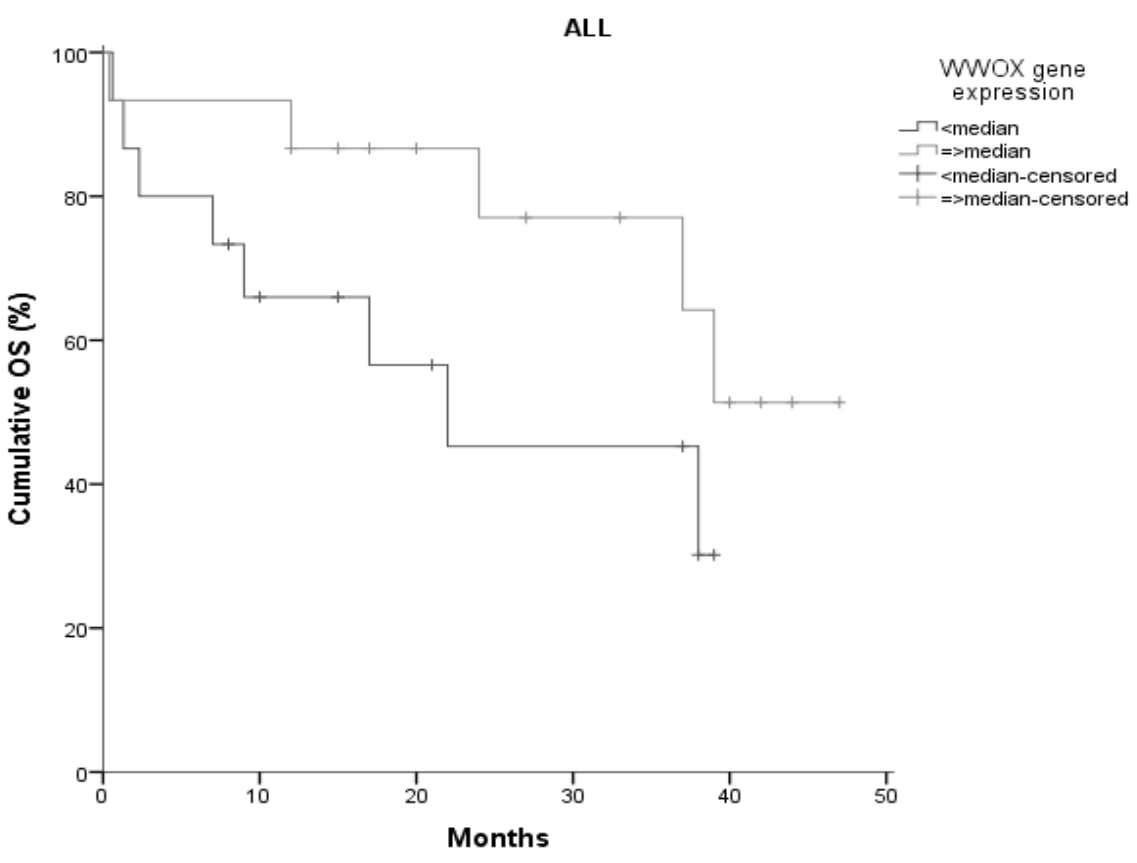

Figure 2: Kaplan-Meier curve for overall survival (OS).

status of WWOX may aid in the development of future treatment approaches for ALL.

\section{Conclusions and Future Directions}

As far as we can tell, this is the first investigation regarding the role of the WWOX gene in the pathogenesis of human leukemia. Because the loss of WWOX expression is common but the gene deletion is not so frequent, epigenetic changes of the WWOX gene such as promoter methylation might also be involved in the pathogenesis of leukemia. Future investigation into the epigenetic regulation of the WWOX gene will shed more light into the early event leading to the loss of the WWOX tumor suppressor gene and provide new therapeutic 
Citation: Elbossaty WF, Malak C, Elghanam DM (2015) Prognostic Relevance of Ww-Oxidoreductase Gene Expression in Patients with Acute Lymphoblastic Leukemia. J Cancer Sci Ther 7: 302-307. doi:10.4172/1948-5956.1000367

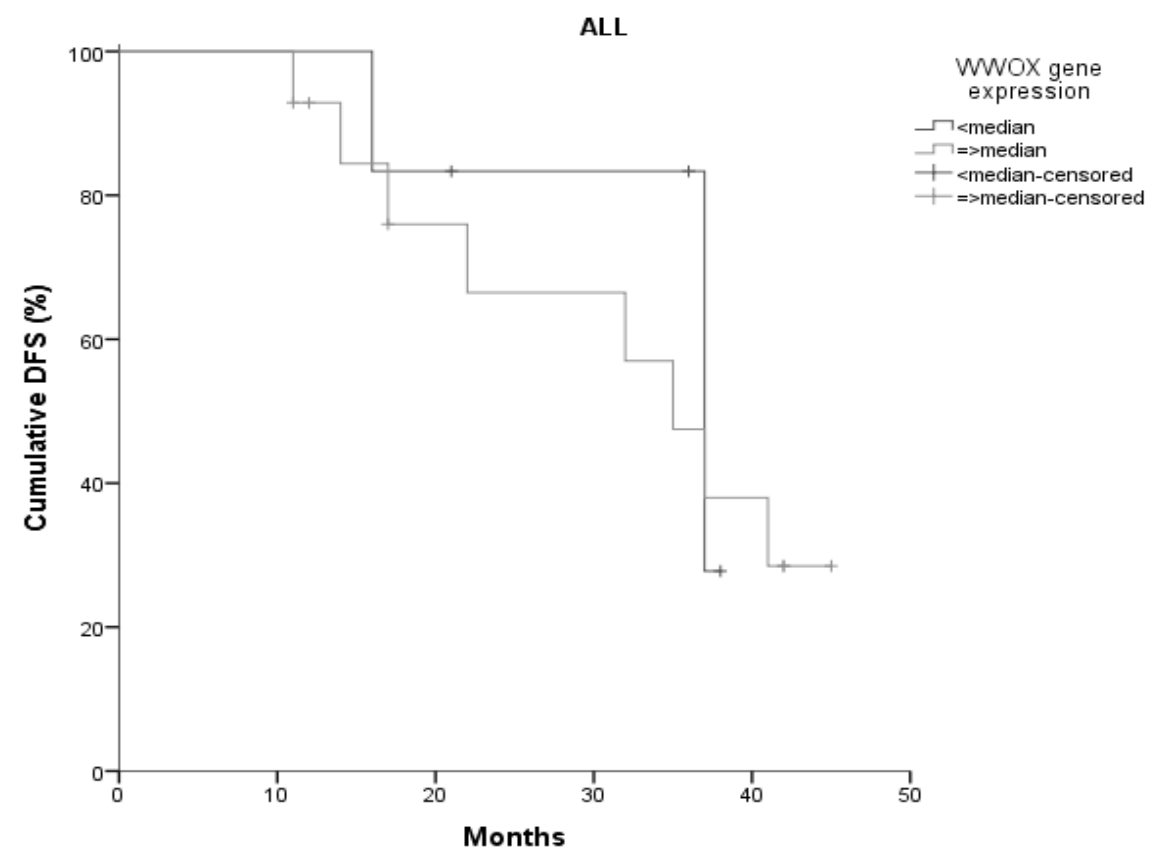

Figure 3: Kaplan-Meier curve for disease free survival (DFS)

\begin{tabular}{|c|c|c|c|}
\hline & P value & Odd ratio high expression/low expression & 95\% Cl for relative risk \\
\hline Complete remission & $0.010^{*}$ & 2.1 & $0.03-4.61$ \\
\hline Relapse & $0.0494^{*}$ & 2.46 & $0.187-2.41$ \\
\hline Refractory & 0.2 & 0.05 & $0.01-0.32$ \\
\hline
\end{tabular}

Table 6: Odd ratio assessment of high and low expression of WWOX gene.

\begin{tabular}{|c|c|c|c|c|c|c|c|c|c|}
\hline \multirow{6}{*}{ ALL } & & \multicolumn{2}{|c|}{ Univariate } & \multirow[b]{2}{*}{$95 \% \mathrm{Cl}$} & & \multicolumn{2}{|c|}{ Multivariate } & \multirow[b]{2}{*}{$95 \% \mathrm{Cl}$} & \multirow{3}{*}{1.012} \\
\hline & & $\mathbf{P}$ & HR & & & $\mathbf{p}$ & HR & & \\
\hline & Age (years) & 0.194 & 0.963 & 0.921 & 1.006 & 0.125 & 0.957 & 0.904 & \\
\hline & BM blasts (\%) & 0.556 & 1.008 & 0.981 & 1.036 & 0.608 & 1.008 & 0.978 & 1.039 \\
\hline & Immunophenotypes & 0.899 & 0.907 & 0.2 & 4.107 & 0.295 & 0.383 & 0.064 & 2.306 \\
\hline & WWOX(above median versus below median) & $0.022^{*}$ & 0.406 & 0.13 & 0.974 & $0.010^{*}$ & 0.347 & 0.095 & 0.872 \\
\hline
\end{tabular}

Table 7: Univariate and multivariate analysis for prediction of OS in all studied patients.

opportunities for acute leukemia with the emerging drugs that reverse the cancer associated epigenetic alteration.

\section{References}

1. Sahu GR, Das BR (2005) Alteration of p73 in pediatric de novo acute lymphoblastic leukemia. Biochem Biophys Res Commun 327: 750-755.

2. Inaba H, Greaves M, Mullighan CG (2013) Acute lymphoblastic leukaemia. Lancet 381: 1943-1955.

3. Seiter K, Sarkodee-Adoo C, Talavera F, Sacher RA, Besa EC (2014) Acute Lymphoblastic Leukemia.

4. Merza MS (2015) Immunohistochemical assessment of tumor suppressor gene Wwox in relation to proliferative marker KI67 proteins expression in giant cell lesions of the jaws and giant cell tumor of long bones. J Bagh Coll Dentistry 27: 121-127.

5. Bednarek AK, Laflin KJ, Daniel RL, Liao Q, Hawkins KA, et al. (2000) WWOX, a novel WW domain-containing protein mapping to human chromosome 16q23.324., a region frequently affected in breast cancer. Cancer Res 60: 2140-2145.

6. Li J, Liu J, Ren Y, Yang J3, Liu P1 (2014) Common Chromosomal Fragile Site Gene WWOX in Metabolic Disorders and Tumors. Int J Biol Sci 10: 142-148.
7. Swerdlow SH, Campo E, Harris NL (2008) WHO classification of 19hematopoietic and lymphoid tissues. Lyon, France.

8. Chang HT, Liu CC, Chen ST, Yap YV, Chang NS et al. (2014) WW domaincontaining Oxidoreductase in neuronal injury and neurological diseases. Oncotarget 5: 11792-11799.

9. Szu-Jung C, Shenq-Shyang H, Nan-Shan C (2013) Role of WWOX and NF-B in lung cancer progression. Translational Respiratory Medicine 1:15.

10. Gourley C, Paige AJ, Taylor KJ, Scott D, Francis NJ et al (2005) WWOX mRNA expression profile in epithelial ovarian cancer supports the role of WWOX variant 1 as a tumour suppressor, although the role of variant 4 remains unclear. Int. J. Oncol 26: 1681-1689.

11. Driouch K, Prydz H, Monese R, Johansen H, Lidereau R, et al. (2002) Alternative transcripts of the candidate tumor suppressor gene, WWOX, are expressed at high levels in human breast tumors. Oncogene 21: 1832-1840.

12. Paige AJ, Taylor KJ, Taylor C, Hillier SG, Farrington S, et al. (2001) WWOX: a candidate tumor suppressor gene involved in multiple tumor types. Proc Natl Acad Sci U S A 98: 11417-11422.

13. Agrawal S, Unterberg M, Koschmieder S, zur Stadt U, Brunnberg U, et al. (2007) DNA methylation of tumor suppressor genes in clinical remission predicts the relapse risk in acute myeloid leukemia. Cancer Res 67: 1370-1377. 
Citation: Elbossaty WF, Malak C, Elghanam DM (2015) Prognostic Relevance of Ww-Oxidoreductase Gene Expression in Patients with Acute Lymphoblastic Leukemia. J Cancer Sci Ther 7: 302-307. doi:10.4172/1948-5956.1000367

14. Bednarek AK, Keck-Waggoner CL, Daniel RL, Laflin KJ, Bergsagel PL, et al. (2001) WWOX, the FRA16D gene, behaves as a suppressor of tumor growth. Cancer Res 61: 8068-8073.

15. Chen X, Zhang H, Li P, Yang Z, Qin L, et al. (2013) Gene expression of WWOX FHIT and p73 in acute lymphoblastic leukemia. Oncol Lett 6: 963-969.

16. Esteller M (2002) CpG island hypermethylation and tumor suppressor genes: a booming present, a brighter future. Oncogene 21: 5427-5440.

17. Roman-Gomez J, Jimenez-Velasco A, Castillejo JA (2004) Promoter hypermethylation of cancer-related genes: A strong independent prognostic factor in acute lymphoblastic leukemia. Blood. 104: 2492-2498.

18. Nephew KP, Huang TH (2003) Epigenetic gene silencing in cancer initiation and progression. Cancer Lett 190: 125-133.
19. Lin JT, Tzai TS, Liao CY, Wang JS, Wu TT, et al. (2013) WWOX protein expression varies among RCC histotypes and downregulation of WWOX protein correlates with less-favorable prognosis in clear RCC. Ann Surg Onco 20: 193-199.

20. Nunez MI, Rosen DG, Ludes-Meyers JH, Abba MC, Kil H, et al (2005) WWOX protein expression varies among ovarian carcinoma histotypes and correlates with less favorable outcome. BMC Cancer 5: 64

21. Tsai CW, Lai FJ, Sheu HM, Lin YS, Chang TH, et al (2013) WWOX suppresses autophagy for inducing apoptosis in methotrexate-treated human squamous cell carcinoma. Cell death and disease 4: e792.

22. Chiang MF, Chou PY, Wang WJ, Sze Cl, Chang NS (2013) Tumor Suppressor WWOX and p53 Alterations and Drug Resistance in Glioblastomas. Front Oncol 3: 43. 